\title{
A METAPSICOLOGIA DO MASOQUISMO: O ENIGMA DO MASOQUISMO FEMININO E SUA RELAÇÃO COM A FANTASIA MASCULINA
}

Carolina Nassau Ribeiro

Carolina Nassau Ribeiro

Universidade

Federal de Minas

Gerais (UFMG),

Mestre pelo

Programa de

Pós-Graduação em

Psicologia, Belo

Horizonte/MG,

Brasil.

RESUMO: Ao longo deste artigo, acompanharemos quais foram as proposições freudianas sobre o masoquismo, apontando suas inovações bem como as alterações realizadas durante a construção de seu arcabouço teórico. Destacaremos o momento da criação do termo masoquismo feminino e, logo depois, abordaremos a tese lacaniana que assevera que o masoquismo feminino é uma fantasia do desejo masculino, sendo que, quando esse desejo incide nas mulheres, revela-se que é apenas uma das máscaras utilizadas pela mulher para enlaçar a fantasia masculina.

Palavras-chave: masoquismo; feminino; fantasia.

ABSTRACT: The metapsychology of masochism: the enigma of female masochism and its relationship to male fantasy. Throughout this article, we will follow what were the Freudian propositions on masochism, pointing their innovations as well as the changes made during the construction of psychoanalytic theoretical framework. We will highlight the moment of creation of the term feminine masochism, and soon after, we will address the Lacanian thesis that asserts that female masochism is a fantasy of male desire, and, when this desire focuses on women, it turns out it is just one of the masks used by women to ensnare the male fantasy.

Keywords: masochism; female; fantasy.

DOI - http://dx.doi.org/10.1590/1809-44142017002009 


\section{A TEORIA PSICANALÍTICA DO MASOQUISMO DE FREUD A LACAN}

As proposições de Freud acerca do masoquismo passaram por várias modificações ao longo de sua obra. Nos Três ensaios sobre a teoria da sexualidade (FREUD, 1905/1974), o autor nos informa que decidiu lançar mão do termo masoquismo, assim sugerido pelo psiquiatra Krafft-Ebing, pois esse termo, extraído da literatura de Sacher-Masoch, indica não só o prazer na dor, tal qual o termo algolagnia ${ }^{1}$, mas também o prazer obtido em qualquer forma de sujeição ou humilhação. Já nesse momento incipiente de sua formulação teórica, ele denuncia que as raízes do sadismo e do masoquismo pertencem "às características universais da vida sexual” (FREUD, 1905/1974, p. 149) e que não se limitam à perversão.

Nesse artigo, ele anuncia a existência da sexualidade na infância e demonstra que ela se manifesta como perversa e polimorfa. É surpreendente constatar que, ao estudar o masoquismo no âmbito das perversões, Freud se depara com a fantasia masoquista inconsciente, característica da neurose. A condição perversa e polimorfa da sexualidade humana é velada pelo recalque, o que faz com que Freud formule a tese de que a neurose é o negativo da perversão: "Portanto, os sintomas se formam, em parte, às expensas da sexualidade anormal; a neurose é, por assim dizer, o negativo da perversão" (FREUD, 1905/1974, p. 155, grifos no original).

Vale destacar que Freud inova porque retira o masoquismo do âmbito das patologias perversas e passa a considerá-lo como um dos componentes da sexualidade humana; tanto o desenvolvimento quanto a satisfação da sexualidade humana são marcados por tendências sádicas e masoquistas. A perversão só pode ser considerada uma aberração sexual quando ocorre uma fixação em um dos componentes da sexualidade. O masoquismo é perverso apenas quando a satisfação pulsional está exclusivamente condicionada à dor física ou psíquica advinda do objeto sexual. Conforme as articulações de Freud deste período, o masoquismo pode ser relacionado ao feminino, a partir da problemática e tão debatida consideração de que ambos possuem características passivas. Ao longo deste artigo, faremos uma distinção entre o masoquismo e o feminino, demonstrando que ambos não podem ser categorizados como passivos. ${ }^{2}$

Nesse momento da teoria psicanalítica, o sadismo é considerado um fenômeno primário em relação ao masoquismo. A pulsão de domínio pertence às pulsões do eu e é responsável pela posse do objeto; a pulsão sádica é a pulsão de domínio a serviço das pulsões sexuais, o que possibilita afirmar que a crueldade está intimamente vinculada às pulsões sexuais. É válido enfatizar que Freud, nesse

\footnotetext{
${ }^{1}$ Freud (1905) indica que extraiu o termo algolagnia de um autor chamado Schrenck-Notzing, cujo artigo sobre o assunto foi publicado em 1899.

${ }^{2}$ As relações entre masoquismo e feminilidade são abordadas por Colette Soler (1998), que nos aponta que: “[...] a tese 'mulher masoquista' não é a tese freudiana. Freud a introduziu e explorou, mas soube reconhecer que não era...” (SOLLER, 1998, p. 212).
} 
momento, não faz distinção entre a pulsão sádica e a masoquista, propondo, então, o masoquismo como um fenômeno secundário em relação ao sadismo: o masoquismo seria um retorno do sadismo sobre o próprio corpo. De acordo com Freud, a “análise clínica dos casos extremos de perversão masoquista mostra a colaboração de uma ampla série de fatores (como o complexo de castração e a consciência de culpa) no exagero e fixação da atitude passiva originária” (FREUD, 1905/1974, p. 149).

Em Pulsão e suas vicissitudes (FREUD, 1915/1974), encontramos novas contribuições acerca do problema do masoquismo. É notável a influência exercida pela introdução do conceito de narcisismo para a abordagem dos dois primeiros destinos da pulsão, na medida em que "se acham na dependência da organização narcisista do ego” (FREUD, 1915/1974, p. 153). No primeiro, ocorre uma transformação da finalidade pulsional de ativa para passiva e, no segundo, o retorno da pulsão para o próprio eu.

Inicialmente, Freud supunha uma transformação direta da pulsão sádica em masoquista. Nesse momento, porém, provavelmente sob os efeitos da teoria do narcisismo, inclui um terceiro tempo no retorno da pulsão sobre o próprio eu. No primeiro tempo, o sadismo é exercido contra outra pessoa colocada no lugar de objeto. No segundo, esse objeto é deixado de lado e a pulsão é investida na própria pessoa, transformando a finalidade pulsional de ativa em passiva. Todavia, para a realização da meta masoquista, é necessário um terceiro tempo, no qual uma terceira pessoa é colocada na posição ativa, como um algoz: “Também aqui a satisfação segue o caminho do sadismo original, voltando o ego passivo, em fantasia, ao seu papel inicial, que foi agora, de fato, assumido pelo sujeito estranho” (FREUD, 1915/1974, p. 149).

Vale ressaltar que, mais uma vez, ao falar do masoquismo, Freud o relaciona com a voz reflexiva média que é uma categoria da gramática grega clássica cuja conjugação expressa um retorno da ação sobre o próprio sujeito, por exemplo: fazer-se apanhar, fazer-se objeto de uma determinada ação ou até mesmo torturar-se. Trata-se de uma posição ativamente passiva, o que leva Freud a esclarecer que é o masoquista quem escreve o texto de seu espancamento. Consideramos o uso da voz reflexiva média como um indicativo da posição ativa do masoquista, apesar do seu véu de passividade, demonstrando que é ele quem procura alguém que fique na posição de torturá-lo.

Para Lacan (1964/1998), o sujeito é sempre passivo em relação às impressões do mundo exterior. Sua atividade estaria, portanto, limitada ao campo de suas próprias pulsões. A atividade da pulsão consiste em "se fazer": se fazer ver, no caso da pulsão escópica; se fazer comer, na pulsão oral e se fazer defecar, na pulsão anal. Ele ressalta que, no domínio pulsional, a distinção entre passividade e atividade é puramente gramatical, mas é essa característica — a de ter uma 
gramática - que revela como a linguagem altera o instinto, desnaturaliza-o e, assim, define a sexualidade humana. É possível inferirmos que tanto Freud como Lacan estão tocando em pontos que se equivalem, a saber, a atividade que está implícita na passividade: “De fato, salta aos olhos que, mesmo em sua pretensa fase passiva, o exercício de uma pulsão, masoquista por exemplo, exige que o masoquista, se ouso me exprimir assim, trabalhe feito um burro" (LACAN, 1964/1998, p. 189, grifo nosso).

Ora, o uso da voz reflexiva média nos remete à vocação pedagógica e persuasiva, sublinhada por Deleuze (1983) como sendo característica dos personagens "masoquistas" de Sacher-Masoch. São eles que, ativamente, convencem a mulher despótica de lhes aplicar crueldades e castigos. Na obra $A$ vênus das peles (1983), o personagem principal, Severino, não só convence como também doutrina a "Vênus das peles" para que ela seja tão mais atroz e cruel do que ele pode imaginar.

\section{A FANTASIA MASOQUISTA E SUA RELAÇÃO COM A CONSTITUIÇÃO DO SUJEITO}

Podemos considerar o texto Uma criança é espancada - uma contribuição ao estudo da origem das perversões sexuais (FREUD, 1919/1974) como um avanço do autor no estudo sobre o elemento masoquista presente na clínica das neuroses. Freud constata que as fantasias sádicas ou masoquistas podem aparecer tanto na histeria como na neurose obsessiva, e que seu surgimento ocorre na primeira infância, por motivos contingentes. Tais fantasias geram uma mistura de prazer e repugnância e, posteriormente, são submetidas ao recalcamento, substituídas por uma formação reativa ou sublimadas. O autor afirma que elas são a marca de um traço primário de perversão. O pressuposto é que o sadismo transforma-se em masoquismo pela influência da culpa como efeito do recalque. Podemos observar a tentativa de Freud de organizar a fantasia por meio da formulação de uma frase que, em cada etapa, indica, numa versão encenada, a relação do sujeito com o objeto.

Na primeira fase, ainda num período muito precoce, não se sabe se essa fantasia é sádica ou masoquista, pois quem a cria não é o mesmo que espanca. O material ao qual o analista tem acesso é escasso: "O meu pai está batendo na criança (que eu odeio)”, provavelmente um irmão ou uma irmã. Freud interpreta o conteúdo dessa fantasia como incestuoso, pois a cena de espancamento compensa o ciúme do filho e não pode evitar o destino do recalcamento.

A segunda fase da fantasia é masoquista e submetida ao recalcamento: "Eu estou sendo espancado pelo meu pai". Freud enfatiza que essa fase é a mais importante, pois nunca teve existência real, o que implica que o mais importante não é a dor física, mas os aspectos psíquicos, tais como humilhação e submissão, que são revelados pela linguagem. Os enunciados são essencialmente maso- 
quistas e esse é o único tempo em que o sujeito aparece na primeira pessoa, o que revela a índole masoquista do eu. Para Freud, a essência do masoquismo seria a junção do amor com o sentimento de culpa, cuja causa emana do amor incestuoso. A culpa modifica o conteúdo da fantasia de maneira regressiva. Ser amado pelo pai se torna, então, ser espancado por ele: “Esse 'ser espancado’ é agora uma convergência de culpa e do amor sexual. Não é apenas o castigo pela relação genital proibida, mas também o substituto regressivo daquela relação" (FREUD, 1919/1974, p. 237). Destacam-se, nessa fase, aspectos que merecem ser enfatizados: se a fantasia é um substituto da relação sexual proibida, significa que ela pode ser considerada tanto uma grande fonte de prazer quanto de sofrimento. Ora, a conjunção de prazer com sofrimento é o que lhe fornece a cunhagem masoquista.

$\mathrm{Na}$ terceira fase da fantasia, o material a que temos acesso é: "O meu pai (ou um substituto paterno) está batendo nas crianças, ele só ama a mim”. Essa fantasia é mais familiar à consciência e possui uma maior riqueza na elaboração de sua ficção. A característica essencial desse enunciado é seu caráter sádico, além de sua ligação a uma forte excitação sexual. Segundo Freud, embora a fantasia seja sádica, a satisfação que dela emana é masoquista; trata-se somente de uma permuta da fantasia inconsciente, pois as crianças aqui espancadas nada mais são que os substitutos da própria criança que fantasia.

Para Lacan (1958/1999), o texto acima citado é de suma importância para a clínica psicanalítica, por se ocupar de uma das mais relevantes fontes de satisfação pulsional. Ele ressalta que a primeira fase da fantasia situa-se no período pré-edípico e surge a partir da relação triangular entre o sujeito, o irmão e o pai, pois aquele que é espancado nada mais é que o seu primeiro rival. Para o autor, a importância da primeira fase da fantasia reside na constatação de que o outro rival não é amado pelo pai e é por esse meio que o pai assumirá seu valor para o sujeito.

“O pai recusa, nega seu amor à criança espancada, irmãozinho ou irmãzinha. É por haver uma denúncia da relação de amor e humilhação que esse sujeito é visado em sua existência de sujeito. Ele é objeto de uma sevícia, e essa sevícia consiste em negá-lo como sujeito, em reduzir a nada a sua existência de desejante, em reduzi-lo a um estado que tende a aboli-lo como sujeito. Meu pai não o ama, eis o sentido da fantasia primitiva, e é isso que dá prazer ao sujeito - o outro não é amado, ou seja, não é estabelecido na relação propriamente simbólica. É por esse meio que a intervenção do pai assume seu valor primordial para o sujeito, aquele do qual dependerá tudo o que vem depois.” (LACAN, 1958/1999, p. 246, grifo nosso) 
O autor salienta, contudo, que, nessa primeira fase, a problemática ultrapassa aquilo que chamaríamos de ódio em relação ao rival e localiza-se no fato de, para essa criança, a fantasia se inscrever. É a existência do amor do pai para com aquele semelhante cuja presença aponta para uma alteridade radical. O rival existe, é amado pelo pai e também espancado por ele.

Na segunda fase, de acordo com Lacan, o sujeito encontra na fantasia masoquista uma solução para a operação de um ato simbólico. A mensagem que é veiculada não é "meu pai me bate", mas "o rival não existe, não é nada em absoluto", o que significa dizer "eu (sujeito da fantasia) existo e sou amado". A fantasia masoquista permite que aquele sujeito se localize, se inscreva, faça sua marca no mundo simbólico, mas, como essa fantasia não chega ao sujeito, será construída em análise e a única coisa que dela persistirá será o chicote como material significante, que se tornará, então, o pivô da relação do sujeito com Outro: “[...] o que intervém, acima de tudo, é alguma coisa que risca o sujeito, que o barra, que o abole, alguma coisa de significante” (LACAN, 1958/1999, p. 250).

Essa fase é a mais importante, pois é por meio do masoquismo primordial que o sujeito se realiza e se localiza na dialética do significante. Verifica-se, portanto, a importância da passagem da primeira fase para a segunda, já que a criança vê no pequeno rival a possibilidade de erigir-se como sujeito, mesmo que à custa de sua anulação subjetiva, ou seja, pela marca de um traço de subtração.

Na terceira fase, o sujeito será representado pela multiplicação indefinida de indivíduos sendo espancados. Essa será, portanto, a posição a ser reeditada pelo sujeito nas suas repetições e nos seus sintomas. Lacan propõe que essa posição seja traduzida com a expressão "Bate-se numa criança”, destacando, dessa forma, o valor do pronome indefinido "se”, já que, nesse lugar indefinido, qualquer um poderá ocupar o lugar daquele que bate. É somente num momento posterior que o sujeito poderá interpretá-la como sendo ocupada pela figura paterna e seus substitutos. Podemos supor que tal sugestão de tradução nos remeta à voz reflexiva média da gramática grega, já mencionada neste artigo, cuja especificidade foi destacada por Freud e que, do mesmo modo, coloque o sujeito como fabricante ativo de sua fantasia masoquista.

\section{MASOQUISMO FEMININO}

A teoria freudiana do masoquismo é modificada substancialmente a partir do conceito de pulsão de morte e do consequente fracasso do princípio do prazer como condutor principal da vida psíquica.

No texto Além do princípio de prazer (FREUD, 1920/1974), o pai da psicanálise começa a supor, a partir da análise de sonhos traumáticos, que o masoquismo poderia ser primário em relação ao sadismo e, em 1924, escreve O problema eco- 
nômico do masoquismo, em que o masoquismo primário é considerado como certo. Nesse texto, o autor questiona o porquê da existência do masoquismo na vida psíquica dos seres humanos, tendo em vista a hipótese de sermos governados pelo princípio do prazer. O prazer coincidiria com uma queda da tensão psíquica e o desprazer, com um aumento dessa tensão. Freud conclui que não seria o fator quantitativo que determinaria o estado de prazer ou desprazer, mas o fator qualitativo. Uma vez que não consegue determinar qual seria esse fator qualitativo, Freud menciona possíveis determinantes, como se pode notar na seguinte afirmação: "Se pudéssemos dizer o que é essa característica qualitativa, estaríamos muito mais avançados em psicologia. Talvez seja o ritmo, a sequência temporal de mudanças, elevações e quedas na quantidade de estímulos" (FREUD, 1924/1974, p. 200, grifo nosso). Podemos conjecturar que o fator econômico seria o responsável pelo atributo da qualidade. Se o prazer é obtido pela elevação da intensidade de energia pulsional, a qualidade é dada no movimento de retorno da pulsão que, após contornar o objeto, retorna para o próprio eu.

Freud, então, classifica o masoquismo em três formas fenomênicas: o masoquismo erógeno ou primário, o moral e o feminino. O masoquismo erógeno é primário em relação à pulsão sádica, perpassa todas as fases do desenvolvimento da libido e está na base das outras duas formas de manifestação.

O masoquismo moral relaciona-se com o supereu, que, com sua ferocidade, acusa o eu e o pune por não ser a imagem e semelhança do ideal. O masoquismo chamado de feminino é uma fantasia do homem, e é assim caracterizado por representar-se por meio do que Freud nomeia como sendo um traço negativo, tal como podemos acompanhar na seguinte citação:

"Por essa razão, chamei essa forma de masoquismo, a potiori por assim dizer [isto é, com base em seus exemplos extremos], de forma feminina, embora tantas de suas características apontem para a vida infantil. Essa estratificação superposta do infantil e do feminino encontrará posteriormente uma explicação simples. Ser castrado - ou ser cegado, que o representa - com freqüência deixa um traço negativo de si próprio nas fantasias, na condição de que nenhum dano deve ocorrer precisamente aos órgãos e aos olhos." (FREUD, 1924/1974, p. 203, grifos nossos)

O fato de Freud ter nomeado de feminino um tipo de masoquismo sempre foi motivo de muita polêmica. Por que Freud escolheu o termo "feminino" para caracterizá-lo? Seria o masoquismo uma característica inerente à feminilidade? Podemos realmente supor que existiria uma característica masoquista intrínseca à posição feminina? Se essa fosse a sua tese, poderíamos afirmar que, do ponto de vista do psicanalista, as mulheres se regozijariam com o sofrimento, com o aviltamento e com as sevícias. Consideramos possível demonstrar, entretanto, 
que os elementos encontrados no texto freudiano nos fornecem subsídios para afirmar que o fato de um dos tipos de masoquismo ser por ele nomeado de feminino não significa que se esteja fazendo uma equivalência entre os termos.

É claro que o fato de ele ter atribuído ao feminino e ao masoquismo características passivas, ainda que apenas no início de sua produção teórica, pode ter contribuído para elaborações teóricas polêmicas sobre o tema por parte de alguns psicanalistas, como, por exemplo, Hélène Deutsch ${ }^{3}$. Em contrapartida, como foi evidenciado, o masoquista não é passivo; é ele quem conduz ativamente a cena do espancamento, muitas vezes sob o disfarce da passividade.

Retomaremos, então, os indícios que ele nos deixa ao longo de O Problema econômico do masoquismo. Primeiramente, como já ressaltamos, ele localiza que o masoquismo feminino é um modo de masoquismo encontrado nos homens e curiosamente afirma que, dentre as formas de masoquismo destacadas, essa é a menos enigmática. Estaria se referindo a fantasias que aparecem tanto na neurose como na perversão, cujo conteúdo seria o de ser batido, maltratado, rebaixado e coagido a uma obediência incondicional. Tais fantasias indicariam que o masoquista quer ser tratado como uma criança desamparada e travessa. Freud ressalta ainda que, em alguns casos, as fantasias eram de ser castrado, copulado ou dar à luz um bebê, características localizadas como sendo femininas. Dessa forma, como pudemos verificar na citação acima, ele revela que escolheu o nome masoquismo feminino pelo fato de suas fantasias apresentarem um "traço negativo" — ser castrado ou cegado — , mas alega que muitas de suas características se assemelham à vida infantil. É possível supor que a aproximação entre o masoquismo e o feminino encontra-se no fato de ambos inscreverem sua marca por meio de um traço negativo.

Essa forma de masoquismo é retratada como sendo, por um lado, uma “expressão da natureza feminina” (FREUD, 1924/1974, p. 201) — o que não significa que ele esteja nas mulheres - e, por outro, como sendo encontrado em indivíduos do sexo masculino, pois, nas palavras de Freud: "Possuímos suficiente familiaridade com esse tipo de masoquismo nos homens [...]” (FREUD, 1924/1974, p. 202). O que ele aponta é que as fantasias masoquistas transportam o indivíduo para uma " [...] situação caracteristicamente feminina; elas significam, assim, ser castrado, ou ser copulado, ou dar à luz um bebê” (FREUD, 1924/1974, p. 202203, grifo nosso). Todos esses indícios demonstram que o masoquista busca algo

\footnotetext{
${ }^{3}$ Hélène Deutsch (1884-1982), além de aluna, foi paciente de Freud e tornou-se a principal defensora da teoria de que o feminino possui uma característica masoquista que lhe é inata. Seu livro Psicología de la mujer (1947) contém uma série de hipóteses sobre a constituição e o desenvolvimento da sexualidade feminina, nas quais o masoquismo e a passividade são considerados os seus pilares, todos eles auxiliados por fundamentos biológicos. Essa autora será brevemente citada no final do artigo.
} 
que tem relação com o feminino, que expressa a sua natureza, mas que com ele não coincide. Ser castrado ou ser cegado adquirem o atributo de ser negativizado por uma operação de subtração, colocando-o, assim, em posição semelhante à de uma mulher: "Ser castrado - ou ser cegado, que o representa - com frequência deixa um traço negativo de si [...]” (FREUD, 1924/1974, p. 203, grifo nosso). O traço negativo seria, então, uma marca delineada pelo efeito da comparação imaginária do corpo. Inferimos, portanto, que os traços negativos possibilitaram que Freud estabelecesse uma conexão entre masoquismo e feminino, pois o que eles têm em comum nada mais é do que a marca de uma subtração.

O texto freudiano nos fornece ainda mais uma pista sobre a relação entre masoquismo e feminino quando, no artigo Feminilidade, de 1933, afirma:

\footnotetext{
“A supressão da agressividade das mulheres, que lhes é instituída constitucionalmente e lhes é imposta socialmente, favorece o desenvolvimento de poderosos impulsos masoquistas que conseguem, conforme sabemos, ligar eroticamente as tendências destrutivas que foram desviadas para dentro. Assim, o masoquismo, como dizem as pessoas, é verdadeiramente feminino." (FREUD, 1933/1974, p. 143-144, grifo nosso)
}

Se “o masoquismo é verdadeiramente feminino", podemos inferir que, provavelmente, foi a sexualidade feminina que permitiu a Freud o esclarecimento acerca da gênese do masoquismo. Ora, Freud não afirma que o feminino é masoquista, mas que o masoquismo é feminino.

Pelos motivos expostos, o masoquismo não deve ser considerado uma característica feminina, mas um tipo de masoquismo encontrado em homens e em mulheres cujas fantasias giram em torno de um dano que culmine em um equivalente da castração. O enredo da fantasia masoquista conduz aquele que a produz a uma lesão que imaginariamente equivale à castração. É por devanear a mutilação de uma parte ou de uma função de seu corpo que o masoquista adquire um atributo correspondente à castração imaginária atribuída ao feminino. O feminino está relacionado à incompletude, visto que, na dinâmica da comparação imaginária dos corpos, o que se verifica é que falta às mulheres o membro intumescente relacionado à completude masculina. Assim sendo, a castração é assimilada, ainda que imaginariamente, como sendo um atributo feminino. Consideramos que Freud é extremamente claro ao apontar que não é necessário que o ato de amputação se efetive, pois se trata apenas de fantasia.

\section{MASOQUISMO FEMININO, FANTASIA MASCULINA}

Em seu artigo Diretrizes para um Congresso sobre sexualidade feminina (1958b/2003), Lacan critica explicitamente a hipótese de um masoquismo da mulher e afirma que os 
analistas também têm seus preconceitos, mas que é preciso distinguir o que é preconceito e o que é uma formação do inconsciente. Formula, então, a seguinte questão: “Será que podemos nos fiar no que a perversão deve à invenção masculina, para concluir que o masoquismo da mulher é uma fantasia do desejo do homem?" (LACAN, 1958b/2003, p. 740).

A resposta a essa pergunta foi explicitamente formulada no Seminário - livro 10: a angústia (1962-1963/2005), no qual ele atesta que o masoquismo feminino é uma fantasia masculina. Essa afirmação foi feita por meio do caso clínico de uma mulher atendida por ele, cuja queixa se tecia em torno da mudança de comportamento de seu marido: ele, que outrora a procurava insistente e inconvenientemente, naquele momento, simplesmente desistiu e não mais a procurou. Segundo Lacan, o que especificamente a incomodava poderia ser condensado na seguinte frase: "Não importa que ele me deseje desde que não deseje outras" (LACAN, 1962-1963/2005, p. 207). Essa mesma paciente, quando jovem, se correspondia com um rapaz que, nas palavras dela, havia sido o seu primeiro amor. Eles trocavam cartas cujo conteúdo, de acordo com o relato dessa mulher, era "um tecido de mentiras":

"Eu criava fio a fio um personagem, aquele que eu desejava ser aos olhos dele, e que não era de jeito nenhum. Receio que isso tenha sido uma iniciativa puramente romanesca, e que persegui da maneira mais obstinada, envolvendo-me numa espécie de casulo. E acrescentou, com toda gentileza. Sabe, ele teve dificuldades para se recuperar disso" (LACAN, 1963/2005, p. 208, grifos no original).

Partindo desse caso clínico, Lacan indaga aos analistas acerca da sexualidade feminina e formula algumas respostas. Sua premissa é a de que uma mulher a priori se interessa pelo desejo do outro, uma vez que "seu vínculo com o nó do desejo é bem mais frouxo” (LACAN, 1962-1963/2005, p. 202). Essa frouxidão, decorrente da falta fálica, possibilita que ela se desdobre, se transmute e se disfarce para enlaçar o desejo de um homem. O caso clínico ressaltado nos permite acompanhar que, para atrair o desejo do referido rapaz, ela se disfarçava e, por meio desse "personagem", não só enlaçou o rapaz como também o fez sofrer.

De acordo com a formulação lacaniana, a função fálica, para o homem, é marcada por uma falta que, por sua vez, instaura um campo de desejo no qual se busca um objeto que faça obstáculo a esse buraco. O homem procura um objeto que tampone essa falta, tal qual um objeto fetichista. Esse objeto tem para o homem a significação do velamento da castração. É por esse motivo que Lacan defende a hipótese de que a impostura perversa é predominantemente masculina, já que, para o homem, "o objeto é a condição do desejo. O gozo depende dessa questão” (LACAN, 1962-1963/2005, p. 210). 
"A falta, o sinal menos com que é marcada a função fálica no homem, e que faz com que sua ligação com o objeto tenha que passar pela negativização do falo e pelo complexo de castração, o status do (- $\phi)$ no centro do desejo do homem, é isso que não constitui, para a mulher, um nó necessário.” (LACAN, 1963/2005, p. 202, grifo no original)

A causa do desejo masculino seria condicionada por um objeto com a roupagem de um fetiche. É por esse motivo que Lacan denomina a versão masculina do amor de "fetichista", pois o objeto precisa preencher uma série de condições específicas para se tornar desejável. A mulher desperta a fantasia masculina na medida em que preenche, mesmo que imaginariamente, esses requisitos de estar na posição de objeto, de se fazer objeto causa de desejo para ele. Essa característica do desejo masculino é retomada por Miller (2002), que afirma que esse traço masculino pode ser categorizado como sendo uma "perversão normal do macho”, isto é, o desejo masculino se distinguiria do feminino na medida em que "requer o mais gozar" (MILLER, 2002, p. 18). São os homens que exigem determinadas características em uma mulher para que ela se torne, assim, o objeto causa de seu desejo.

Já nas mulheres, essa operação seguiria outro circuito, pois elas encontram sua satisfação ao capturar o objeto de desejo do homem amado, “o objeto fálico só chega a ela em segundo lugar, e na medida em que desempenha um papel no desejo do Outro" (LACAN, 1962-1963/2005, p. 202). Para elas, o desejo é indeterminado, podendo-se ligar a possibilidades infinitas, pois importa mais fisgar o desejo do Outro do que se fixar a determinadas condições. Dessa forma, Lacan assevera que, quando a perversão ocorre na mulher, trata-se apenas de farsa, de um disfarce, de uma máscara, em que ela encena a "personagem" do que supõe que seja o desejo do Outro: "Para a mulher, o desejo do Outro é o meio para que seu gozo tenha um objeto, digamos, conveniente" (LACAN, 1962-1963/2005, p. 210).

Essa hipótese de Lacan confirma a indicação de Freud de que, para a mulher, importa menos amar do que ser amada. Não foi por acaso que Lacan, possivelmente dando voz a esse apontamento de Freud, lança mão do citado exemplo clínico. Não seria esse aspecto do desejo feminino que a paciente de Lacan revela, ao dizer que pouco importa que o marido a deseje, o que é relevante é que ele não deseje as outras?

Há nesse enunciado certo paradoxo que nos permite inferir que, por não desejar outras, é que o olhar desse homem a institui como uma mulher, como objeto de desejo dele. Ela é amada na medida em que as outras não o são. Importa, portanto, o que ele deseja. É a partir dele que ela se localiza como mulher desejada, mesmo que se queixe quando ele a procura insistentemente. São 
pelos motivos expostos que a forma do amor feminino é nomeada por Lacan de "erotomaníaca”.

Miller (2002) elucida que o desejo feminino passa pelo amor, sendo que esse é condicionado pela castração. Se o amor se manifesta do lado feminino como sendo "erotomaníaco", como sendo um "amor louco", "um amor sem limite” (MILLER, 2002, p. 18), é exatamente porque a mulher se dispõe a se colocar na posição de objeto da fantasia masculina e, a partir dela, receber a sua identidade.

Retomando o problema do masoquismo na mulher, Lacan afirma, mais uma vez, que o masoquismo feminino é uma fantasia masculina (LACAN, 1964/1998, p. 182). Sua hipótese é que essa concepção de um masoquismo inerente à mulher foi sustentada pela cumplicidade e pelo consentimento de algumas psicanalistas, pois, "sem dúvida que aí talvez haja um véu que convém não levantar depressa demais, concernente aos interesses do sexo" (LACAN, 1964/1998, p. 182, grifo nosso). Podemos inferir que Lacan está fazendo uma alusão, ainda que velada, à teoria do masoquismo feminino formulada por Hélène Deutsch. Tal asserção permite deduzir que, possivelmente, a referida teoria só foi validada pelas outras psicanalistas em decorrência das concessões femininas em relação ao desejo do Outro. Estaríamos diante, portanto, de uma resposta à fantasia masculina. Assim, para enlaçar o desejo do Outro, essas psicanalistas sustentaram, ainda que encobertas por um véu, a asserção do masoquismo feminino. Lacan esclarece, ainda, que a tentativa de fazer coincidir o masculino com a atividade e o feminino com a passividade é um recurso metafórico utilizado para nomear o que não se pode perscrutar na diferença entre os sexos e, fazendo alusão à concepção de máscara forjada por Joan Riviere ${ }^{4}$, nos mostra que:

“Levando as coisas ao máximo, pode-se dizer mesmo que o ideal viril e o ideal feminino são figurados no psiquismo por outra coisa que não essa oposição atividade passividade de que eu falava há pouco. Eles saem propriamente de um termo que não fui eu que introduzi, mas com que uma psicanalista rotulou a atitude sexual feminina - é a mascarada." (LACAN, 1964/1998, p. 183, grifo nosso)

Reafirmando a posição de Lacan, Colette Soler (2005) considera que Freud, apesar de ter forjado o termo "masoquismo feminino", não deixa margem para equívocos, pois jamais utilizou o masoquismo para esclarecer o problema do feminino; ao contrário, empregou suas elaborações sobre o segundo para escla-

\footnotetext{
${ }^{4}$ A noção de máscara surgiu em 1929, quando Joan Riviere escreveu o artigo A feminilidade como máscara (1929), no qual demonstra, por meio da análise de um caso clínico, que não existe diferença entre a posição feminina e a máscara. Sua tese é a de que a feminilidade é um artifício com a função tanto de encobrir as fantasias de posse do pênis quanto de proteger a mulher de possíveis ataques masculinos como vingança pelo fato de ela ter se apossado do pênis.
} 
recer os impasses do primeiro. Soler ressalta que a teoria do feminino masoquista manteve-se inquestionável pela sustentação da chamada "masoquista mascarada".

É a própria Colette Soler (1998) quem distingue o masoquista perverso da máscara masoquista feminina, explicando que o masoquista não deixa brechas para o acaso; ele precisa ter o seu gozo garantido por um contrato, pois visa a um "sinal da angústia" no outro: "Ao fazer alarde de uma vontade de gozo afirmada, que pretende realizar-se pela dor, ele de fato realiza um desejo que não sabe e que visa à angústia do Outro [...]” (SOLER, 1998, p. 219).

\section{CONSIDERAÇÕES FINAIS}

A respeito das relações entre o masoquismo e o feminino, demonstramos que as mesmas não visavam esclarecer o problema da feminilidade, mas do masoquismo. Ao retomar a trilha dos textos freudianos, foi possível verificar que o feminino não possui uma característica masoquista que lhe seja inerente. Se Freud classificou um dos tipos de masoquismo com o atributo de feminino, foi por encontrar nas fantasias masoquistas masculinas os chamados "traços negativos" que indicavam a subtração de alguma parte ou função do corpo que poderia equivaler-se à castração, considerada como uma característica feminina.

Tal demonstração nos foi apontada por Lacan, quando lança luz acerca da especificidade do desejo masculino - marcado por um traço de perversão fetichista - assim como sobre o fato de o desejo feminino guiar-se pela vontade de acender o desejo masculino, especificidade caracterizada como a forma fetichista do amor masculino e o modo erotomaníaco de amar da mulher. Ressaltamos que essa maneira erotômana de amar tem como consequência a complacência das mulheres em relação à fantasia masculina, o que engendra a máscara masoquista da mulher.

Podemos inferir, assim, com a contribuição de Lacan, que o suposto masoquismo feminino deve ser concebido como uma das máscaras utilizadas pela mulher, tanto para que ela mesma possa localizar-se na partilha sexual como para enlaçar o desejo de um homem.

Recebido em: 25 de agosto de 2014. Aprovado em: 16 de janeiro de 2015.

\section{REFERÊNCIAS}

ALENCAR, M. L. O. de A. A concepção freudiana da fantasia. In: BERNARDES, A. C. (org.). 10 x Freud. Rio de Janeiro: Azougue, 2005.

ASSOUN, P.-L. Lecciones psicoanalíticas sobre el masoquismo. Buenos Aires: Nueva Visión, 2005. 
BESSA, G. de L. P. Congruências entre o masoquismo e a sexualidade feminina em Sigmund Freud. Dissertação de Mestrado, Programa de Pós-Graduação em Psicologia (Estudos Psicanalíticos), Faculdade de Filosofia e Ciências Humanas, Universidade Federal de Minas Gerais, 2004.

DELEUZE, G. Apresentação de Sacher-Masoch. Rio de Janeiro: Taurus, 1983.

DEUTSCH, H. Masoquismo femenino. In La psicología de la mujer.

Buenos Aires: Editorial Losada, 1947.

FREUD, S. Além do princípio de prazer. Rio de Janeiro: Imago, 1974. (Ed. standard brasileira das obras completas, 18).

Conferência XXXIII: Feminilidade. Rio de Janeiro: Imago, 1974. (Ed. standard brasileira das obras completas, 22).

O problema econômico do masoquismo. Rio de Janeiro: Imago, 1974. (Ed. standard brasileira das obras completas, 19).

Os instintos e suas vicissitudes. Rio de Janeiro: Imago, 1974. (Ed. standard brasileira das obras completas, 14).

O tema dos três escrínios. Rio de Janeiro: Imago, 1974. (Ed. standard brasileira das obras completas, 12).

Sobre o narcisismo: uma introdução. Rio de Janeiro: Imago, 1974. (Ed. standard brasileira das obras completas, 14).

Três ensaios sobre a teoria da sexualidade. Rio de Janeiro: Imago, 1974. (Ed. standard brasileira das obras completas, 7).

Uma criança é espancada. Rio de Janeiro: Imago, 1974. (Ed. standard brasileira das obras completas, 17).

LACAN, J. A angústia (1962-1963). Rio de Janeiro: J. Zahar, 2005. (O seminário, 10).

As formações do inconsciente (1957-1958). Rio de Janeiro: J. Zahar, 1999. (O seminário, 5).

A significação do falo (1958a). In: Outros escritos. Rio de Janeiro: J. Zahar, 2003.

Diretrizes para um Congresso sobre a sexualidade feminina (1958b). In: Outros escritos. Rio de Janeiro: J. Zahar, 2003.

Os quatro conceitos fundamentais da psicanálise (1964). Rio de Janeiro:

J. Zahar, 1998. (O seminário, 11).

MILLER, J.-A. Uma partilha sexual. Clique: Revista dos Institutos Brasileiros do Campo Freudiano. Belo Horizonte, 2003. N. 2.

RIVIERE, J. A feminilidade como máscara. Psychê. São Paulo: Unimarco, 2005. N. 16.

ROUDINESCO, E.; PLON, M. Dicionário de Psicanálise. Rio de Janeiro: J. Zahar, 1998.

SOLER, C. A psicanálise na civilização. Rio de Janeiro: Contra Capa. 1998. O que Lacan dizia das mulheres. Rio de Janeiro: J. Zahar. 2005.

Carolina Nassau Ribeiro

carolnassau@gmail.com 